\title{
PLATON: use of romiplostim to treat chronic primary immune thrombocytopenia
}

\section{An observational, nonintervention study of real-life practice}

\section{Georgi Mihaylov · Barbara Skopec $\cdot$ Zuzana Sninska $\cdot$ Nikolai Tzvetkov · Olga Cerna · Vladlen Ivanushkin · Daniela Niepel · Katja Björklöf · Peter Černelč}

Received: 3 October 2019 / Accepted: 14 January 2020 / Published online: 25 February 2020

(C) The Author(s) 2020

Summary Chronic primary immune thrombocytopenia (ITP) is an autoimmune disease involving the formation of antibodies to thrombocytes, leading to increased platelet destruction and chronic thrombocytopenia. Additionally, impaired platelet production is due to relative thrombopoietin deficiency. Romiplostim, a thrombopoietin receptor agonist, normalized platelet counts in affected patients in randomized controlled trials and real-world observational studies. The present study collected real-world practice data from Central and Eastern Europe, i.e. Slovakia, Slove-

Data availability Amgen holds the source data and all authors had full access to the data. Qualified researchers may request data from Amgen clinical studies. Complete details are available at the following: http://www.amgen. com/datasharing.

Electronic supplementary material The online version of this article (https://doi.org/10.1007/s12254-020-00580-6) contains supplementary material, which is available to authorized users.

\section{G. Mihaylov (ه)}

Clinic of Clinical Hematology, Specialized Hospital

for Active Treatment of Hematology Diseases EAD,

6 Plovdivsko pole Str., 1756 Sofia, Bulgaria

geombulg@gmail.com

\section{B. Skopec $\cdot$ P. Černelč}

Department of Hematology, University Medical Center

Ljubljana, Zaloska cesta 7, 1000 Ljubljana, Slovenia

B. Skopec

barbara.skopec@kclj.si

P. Černelč

peter.cernelc@kclj.si

\section{Z. Sninska}

Department of Hematology and Blood Transfusion,

University Hospital St. Cyril and Metod,

Antolská 11, 85107 Bratislava, Slovakia

zuzana.sninska@gmail.com nia, Bulgaria, Russia, and Czech Republic, between December 2010 and July 2017. This was an ambidirectional observational, noninterventional cohort study within the approved romiplostim indication. Onehundred patients were analyzed. Prior to romiplostim start, $98 \%$ had received other ITP medications and, in the prior 6 months, $40 \%$ had experienced bleeding events. Romiplostim was started 1.92 years (median) after ITP diagnosis. The median mean on-study dose was $2.62 \mu \mathrm{g} / \mathrm{kg} /$ week. During romiplostim treatment, platelet counts rapidly normalized to $>50 \times 10^{9} / \mathrm{L}, 20 \%$

\author{
N. Tzvetkov \\ Clinic of Hematology, University Multiprofile Hospital \\ for Active Treatment “Dr. Georgi Stranski” EAD, \\ 8A Georgi Kochev Street, 5800 Pleven, Bulgaria \\ tzvetkovn@yahoo.com \\ O. Cerna \\ Department of Clinical Hematology, University Hospital \\ Kralovske Vinohrady, Šrobárova 50, 10034 Prague, Czech \\ Republic \\ olga.cerna@fnkv.cz \\ V. Ivanushkin \\ Department of Biostatistics, Quartesian, Kharkov, Ukraine \\ D. Niepel \\ Global Medical Affairs, Amgen (Global) GmbH, \\ Suurstoffi 22, 6343 Rotkreuz, Switzerland \\ daniela.niepel@gmx.net \\ K. Björklöf \\ Medical Affairs, Amgen (Europe North East), \\ Suurstoffi 22, 6343 Rotkreuz, Switzerland \\ katja.bjorklof@amgen.com \\ P. Černelč \\ Department of Biostatistics, Quartesian, \\ 3 Independence Way, Suite 106, Princeton, NJ 08540, USA
}


of patients experienced bleeding events (none grade $3 / 4$ ), and $13 \%$ required splenectomy. At the end of study, $25 \%$ of patients were in remission. One patient experienced serious adverse drug reactions (thrombosis, dysphagia), none were fatal. In conclusion, romiplostim dosing, effectiveness and safety in these unselected ITP patients seemed comparable with observations in clinical trials and similarly designed observational studies.

Keywords Thrombopoietin receptor agonist · Blood platelets $\cdot$ Splenectomy $\cdot$ Bleeding $\cdot$ Remission

\section{Introduction}

Chronic primary immune thrombocytopenia (ITP) is an autoimmune disease characterized by premature degradation and impaired production of platelets [1]. The clinical symptoms include petechiae, hematomas, and mucosal bleeding. The cause of the disease remains unknown. The ITP incidence ranges between 1.6 and 3.9 cases per 100,000 person-years for adults, with an age-specific increase from 60 years onwards [2].

Romiplostim specifically binds to the thrombopoietin receptor and increases and subsequently maintains platelet counts in splenectomized and nonsplenectomized patients, allowing patients to reduce or discontinue concomitant ITP medications [3-5]. The present observational study collected data from Central and Eastern Europe to further evaluate the benefits and risks of the drug in real-life clinical practice.

\section{Materials and methods}

\section{Study design}

This was a single-arm, ambidirectional, observational, noninterventional cohort study conducted between December 2010 and July 2017 as part of an international study program $[4,5]$.

The data were collected from medical files and documented the physicians' own routine practice. No study-specific diagnostic or therapeutic protocol was to be followed. Bleeding was graded according to the World Health Organization scale and documented in a standardized manner [6, 7]. Treatment response was documented as per the physicians' assessment and local hospital definition.

Patient and disease history were collected upon study inclusion. The last available data prior to romiplostim initiation were documented as baseline. Documentation of prior bleeding events covered a period of 6 months prior to romiplostim start. Further data were collected from the first dose of romiplostim onwards over a period of two years, independent of the duration of romiplostim treatment. For further definitions consult the online supplement.

\section{Study objectives}

The main objectives were to describe the study population, the application and dosage of romiplostim and other ITP therapies, romiplostim safety, clinically relevant bleeding events, health care resource usage, and reasons for romiplostim discontinuation.

\section{Eligibility criteria}

Adult ( $\geq 18$ years) ITP patients were included. Patients must have received $\geq 1$ romiplostim administration as per approved indication, i.e. as second-line therapy after splenectomy or failure of other therapies, or before splenectomy when surgery was contraindicated. Patients were excluded, if they previously or concurrently received any thrombopoiesis-stimulating drugs, participated in clinical trials, had been treated with romiplostim before its market introduction, or if they showed hypersensitivity to romiplostim, any excipient, or E. coli-derived proteins.

\section{Ethical considerations}

This study was conducted in accordance with regulations in the participating countries and was approved by local ethical committees (see online supplement). Written informed consent was provided.

\section{Statistical methods}

The statistical analysis was descriptive, and no formal hypothesis was tested. Categorical variables were summarized as number, percentage, and exact 2-sided $95 \%$ confidence intervals (CIs). CIs were based on Poisson distribution. Continuous variables were summarized as mean, $95 \% \mathrm{CI}$, standard deviation, median, interquartile range (IQR), and range. Data were analyzed as documented with no imputation for missing data. Prespecified time windows were allowed for platelet counts and dose information.

\section{Results}

Of the 100 patients analyzed, $27(27 \%)$ discontinued observation; 52 (52\%) discontinued romiplostim, mainly within the first 9 months (Table S1).

Fifty-six patients (56\%) were female. Prior splenectomy had been performed in 23 patients (23\%). The median (IQR) age at diagnosis was 45.0 (26.5; 57.5) years. Forty-nine patients ( $49 \%$ ) had received $\geq 3$ prior ITP therapies, most frequently corticosteroids or intravenous immunoglobulin (IVIg); patients were initiated on romiplostim after a median (IQR) of 1.92 $(0.28 ; 6.73)$ years after ITP diagnosis at a median (IQR) platelet count of $19.0(7.5 ; 42.0) \times 10^{9} / \mathrm{L}$ (Table 1$)$. The median (IQR) time of observation was 24.0 months (23.0; 24.1). 
Table 1 Patient demographics and characteristics

\begin{tabular}{|c|c|}
\hline & $\begin{array}{l}\text { All patients } \\
(N=100)\end{array}$ \\
\hline Female, $n(\%)$ & $56(56.0)$ \\
\hline Age at ITP diagnosis, years - median (IQR) & $45.0(26.5 ; 57.5)$ \\
\hline $\begin{array}{l}\text { Age at initiation of romiplostim, years - median } \\
\text { (IQR) }\end{array}$ & $49.5(34.0 ; 61.0)$ \\
\hline Splenectomized before baseline, $n(\%)$ & $23(23.0)$ \\
\hline $\begin{array}{l}\text { ITP duration at initiation of romiplostim, years - } \\
\text { median (IQR) }\end{array}$ & $1.92(0.28 ; 6.73)$ \\
\hline $\begin{array}{l}\text { Baseline platelet count, } 10^{9} \text { cells } / \mathrm{L} \text { - median } \\
\text { (IQR) }\end{array}$ & $19.0(7.5 ; 42.0)$ \\
\hline \multicolumn{2}{|l|}{ Number of prior ITP therapies ${ }^{\mathrm{a}}$} \\
\hline 0 & $2(2.0)$ \\
\hline 1 & $32(32.0)$ \\
\hline 2 & $17(17.0)$ \\
\hline$\geq 3$ & $49(49.0)$ \\
\hline \multicolumn{2}{|c|}{ Most common ( $\geq 10 \%$ frequency) prior ITP therapies ${ }^{\mathrm{a}}, n(\%)$} \\
\hline Corticosteroids & $91(91.0)$ \\
\hline IVlg & $29(29.0)$ \\
\hline Azathioprine & $14(14.0)$ \\
\hline Platelet transfusion & $10(10.0)$ \\
\hline \multicolumn{2}{|c|}{ Ongoing medications for ITP at initiation of romiplostim, $n$ (\%) } \\
\hline Corticosteroids & $3(3.0)$ \\
\hline \multicolumn{2}{|c|}{$\begin{array}{l}\text { IQR interquartile range; SD standard deviation } \\
\text { aPrior medications include those that have ended prior to initiation of } \\
\text { romiplostim } \\
\text { Patient demographics and characteristics by country are available in Table } \\
\text { S2 in the supplement }\end{array}$} \\
\hline
\end{tabular}

\section{Bleeding prior to romiplostim treatment}

During the 6 months prior to romiplostim initiation, 40 patients $(40 \%)$ experienced bleeding events $(35.9 \%$ of nonsplenectomized, $47.2 \%$ of splenectomized patients), with a median (IQR) of $1.0(1.0 ; 1.0)$ event, mostly petechiae, mucocutaneous hemorrhage, epistaxis, and purpura. The study observation-adjusted prior bleeding event incidence per 100 patient-years (95\% CI) was 130.7 (97.6; 171.4; Table 2).

\section{Hospitalizations prior to romiplostim treatment}

Sixty-two patients (62\%) had a total of 133 prior ITPrelated hospitalizations, mainly due to ITP treatment administration ( $n=78$ hospitalizations; $58.6 \%$ ), bleeding events $(n=21 ; 15.8 \%)$ or other, nonspecified reasons $(n=24 ; 18.0 \%)$. The study observation-adjusted incidence $(95 \% \mathrm{CI})$ of prior hospitalizations per 100 patient-years was 103.8 (86.9; 123.0; Table S2).

\section{Romiplostim exposure}

The initial median weekly dose was $1 \mu \mathrm{g} / \mathrm{kg}$ body weight and the median (IQR) mean weekly dose across the entire observation period was $2.62 \mu \mathrm{g} / \mathrm{kg}$ (1.09; 4.50). Overall, 166 episodes of treatment gaps of $\geq 3$ weeks were counted, mainly due to high platelets
Table 2 Summary of bleeding events

\begin{tabular}{|c|c|}
\hline & $\begin{array}{l}\text { All patients } \\
(N=100)\end{array}$ \\
\hline Entire study period ${ }^{a}$ & $100(100.0 \%)$ \\
\hline Patient experienced any bleeding event & $20(20.0 \%)$ \\
\hline Abnormal vaginal bleeding & $1(1.0 \%)$ \\
\hline $\begin{array}{l}\text { Bleeding from invasive sites, soft tissue or muscu- } \\
\text { loskeletal bleeding }\end{array}$ & 0 \\
\hline CNS bleeding with neurologic symptoms & 0 \\
\hline Conjunctival bleeding & $1(1.0 \%)$ \\
\hline Ecchymosis & $3(3.0 \%)$ \\
\hline Epistaxis & $3(3.0 \%)$ \\
\hline Hematemesis & 0 \\
\hline Hematochezia & $1(1.0 \%)$ \\
\hline Hematoma & $5(5.0 \%)$ \\
\hline Hematuria & 0 \\
\hline Hemoptysis & $1(1.0 \%)$ \\
\hline Melena & $1(1.0 \%)$ \\
\hline Mucocutaneous hemorrhage (oral blood blisters) & $5(5.0 \%)$ \\
\hline Oropharyngeal bleeding & 0 \\
\hline Petechiae & $6(6.0 \%)$ \\
\hline Purpura & $5(5.0 \%)$ \\
\hline Retinal hemorrhage with visual impairment & 0 \\
\hline Other ${ }^{b}$ & $4(4.0 \%)$ \\
\hline $\begin{array}{l}6 \text { Months prior to romiplostim } \\
\text { initialization }\end{array}$ & $100(100.0 \%)$ \\
\hline Patient experienced any bleeding event & $40(40.0 \%)$ \\
\hline Abnormal vaginal bleeding & $5(5.0 \%)$ \\
\hline $\begin{array}{l}\text { Bleeding from invasive sites, soft tissue or muscu- } \\
\text { loskeletal bleeding }\end{array}$ & 0 \\
\hline CNS bleeding with neurologic symptoms & 0 \\
\hline Conjunctival bleeding & 0 \\
\hline Ecchymosis & $2(2.0 \%)$ \\
\hline Epistaxis & $7(7.0 \%)$ \\
\hline Hematemesis & $1(1.0 \%)$ \\
\hline Hematochezia & 0 \\
\hline Hematoma & $5(5.0 \%)$ \\
\hline Hematuria & 0 \\
\hline Hemoptysis & 0 \\
\hline Melena & 0 \\
\hline Mucocutaneous hemorrhage (oral blood blisters) & $8(8.0 \%)$ \\
\hline Oropharyngeal bleeding & $2(2.0 \%)$ \\
\hline Petechiae & $9(9.0 \%)$ \\
\hline Purpura & $6(6.0 \%)$ \\
\hline Retinal hemorrhage with visual impairment & $1(1.0 \%)$ \\
\hline Other ${ }^{b}$ & $3(3.0 \%)$ \\
\hline
\end{tabular}

Percentages are based on the number of patients remained at study at the specified timepoint

Multiple bleeding event occurrence is counted only once per timepoint per event type. Patients may be counted in different categories and percentages may add up to more than $100 \%$.

aPercentages are based on the number of patients in Full Analysis Set 'Bleeding events grouped in the 'other' category are treated as one bleeding event. 
Table 3 Exposure to romiplostim

\begin{tabular}{|c|c|}
\hline & $\begin{array}{l}\text { All patients } \\
(N=100)\end{array}$ \\
\hline Number of patients exposed to romiplostim, $n(\%)$ & $100(100.0)$ \\
\hline \multicolumn{2}{|l|}{ Duration of exposure to romiplostim, months } \\
\hline Mean (SD) & $16.80(9.112)$ \\
\hline Median (IQR) & $23.10(6.70 ; 24.21)$ \\
\hline Range & $0.5-24.4$ \\
\hline $\begin{array}{l}\text { Continuous treatment with romiplostim for } \\
\geq 6 \text { months, } n(\%)\end{array}$ & $65(65.0)$ \\
\hline \multicolumn{2}{|l|}{ Initial dose, $\mu g / k g$} \\
\hline Mean (SD) & $1.2(0.62)$ \\
\hline Median (IQR) & $1.0(1.0 ; 1.0)$ \\
\hline Range & $1-5$ \\
\hline $\begin{array}{l}\text { Number of patients who received initial dose of } \\
1 \mu \mathrm{g} / \mathrm{kg}, n(\%)\end{array}$ & $91(91.0)$ \\
\hline \multicolumn{2}{|l|}{ Mean weekly dose, $\mu \mathrm{g} / \mathrm{kg}$} \\
\hline Mean (SD) & $2.97(2.111)$ \\
\hline Median (IQR) & $2.62(1.09 ; 4.50)$ \\
\hline Range & $0.1-8.4$ \\
\hline \multicolumn{2}{|l|}{ Number of injections } \\
\hline Mean (SD) & $53.6(36.38)$ \\
\hline Median (IQR) & $60.0(14.5 ; 88.5)$ \\
\hline Range & $2-106$ \\
\hline
\end{tabular}

( $n=101 ; 60.8 \%$ ), adverse drug reactions (ADRs; $n=1$; $0.6 \%)$, or other reasons $(n=64 ; 38.6 \%)$. Forty-five patients $(45 \%)$ had no such gaps (Table 3$)$. The median (IQR) time on romiplostim treatment was 23.1 months $(6.7 ; 24.1)$. Reasons for discontinuation of romiplostim are listed in supplemental Table S1.

\section{Bleeding events and platelet counts after romiplostim initiation}

Twenty patients (20\%, Table 2 ) experienced any bleeding event after romiplostim initiation (18.8\% of nonsplenectomized, $22.2 \%$ of splenectomized patients). None were grade $3 / 4$ or fatal. Of these 20 patients, 15 (75\%) already had experienced prior bleeding events. The study observation-adjusted incidence (95\% CI) of bleeding events per 100 patient-years was $42.0(32.9 ; 52.8)$. The median (IQR) platelet count had increased from $19.0 \times 10^{9} / \mathrm{L}(7.5 ; 42.0)$ prior to romiplostim initiation to $>50.0 \times 10^{9} / \mathrm{L}$ one week thereafter, a threshold commonly defined as platelet response [3]. Within the first 6 months the median platelet counts steadily increased before reaching a plateau (Fig. 1).

\section{Concurrent ITP medications after romiplostim initiation}

Ninety-eight patients (98\%) received other ITP medications prior to romiplostim, including corticosteroids ( $n=91 ; 91 \%)$ and IVIg $(n=29 ; 29 \%) ; 49$ patients
(49\%) had $\geq 3$ prior ITP treatments. The number of patients and of individual treatments decreased over time (Fig. 2). Ninety-six patients (96\%) discontinued concurrent ITP therapies and 29 (29\%) started such drugs after romiplostim initiation. Seven patients (7\%) required further ITP treatment after romiplostim discontinuation.

\section{Splenectomies}

Thirteen patients (13\%) required splenectomy because of persistent ITP symptoms $(n=8 ; 61.5 \%$ of splenectomized patients), intolerable side effects ( $n=2,15.4 \%)$, patient request $(n=1 ; 7.7 \%)$, or other reasons $(n=2 ; 15.4 \%)$. Of these 13 patients, $6(46.2 \%)$ already had bleeding events prior to romiplostim, 3 (23.1\%) during observation, and 2 (15.4\%) during both periods. Their median (IQR) prior platelet count was $6.0(3.0 ; 19.0) \times 10^{9} / \mathrm{L}$, increasing to 45.0 $(8.0 ; 163.5) \times 10^{9} / \mathrm{L}$ one week after romiplostim initiation and remaining $>50 \times 10^{9} / \mathrm{L}$ at all but two analyzed timepoints (weeks $2\left[47.0 \times 10^{9} / \mathrm{L}\right]$ and 12 $\left.\left[48.0 \times 10^{9} / \mathrm{L}\right]\right)$.

\section{Treatment outcomes}

At the end of study, 25 patients (25\%) had a durable response/remission of whom 23 patients were able to discontinue romiplostim therapy; 45 (45\%) had active disease and continued to receive treatment, 18 (18\%) had active, untreated disease, and 3 (3\%) had died; for 9 (9\%) ITP status was unknown.

\section{Safety}

Four patients experienced 10 different ADRs; 16 ADR events were documented (Table 4), none fatal. One patient (1\%) experienced two serious ADRs (thrombosis, dysphagia). The exposure-adjusted incidence (95\% CI) per 100 patient-years was $11.4(6.5 ; 18.6)$ for ADRs and $1.4(0.2,5.2)$ for serious ADRs.

\section{Discussion}

The PLATON study showed similar efficacy in realworld clinical practice in Central and Eastern Europe as two similar studies in Western Europe, an international phase IV study [4] and the German PLATEAU study [5].

All three studies showed that a substantial proportion of patients received romiplostim prior to splenectomy. Despite the indication approved at the time of study, i.e. in the post-splenectomy setting or in patients with contraindications to splenectomy, $77 \%$ had not undergone splenectomy before initiating romiplostim (range between countries: 67-92\%). In the international phase IV study this proportion was $66 \%$, with a wide range between countries [4], and $83 \%$ in the German PLATEAU study [5]. From the 


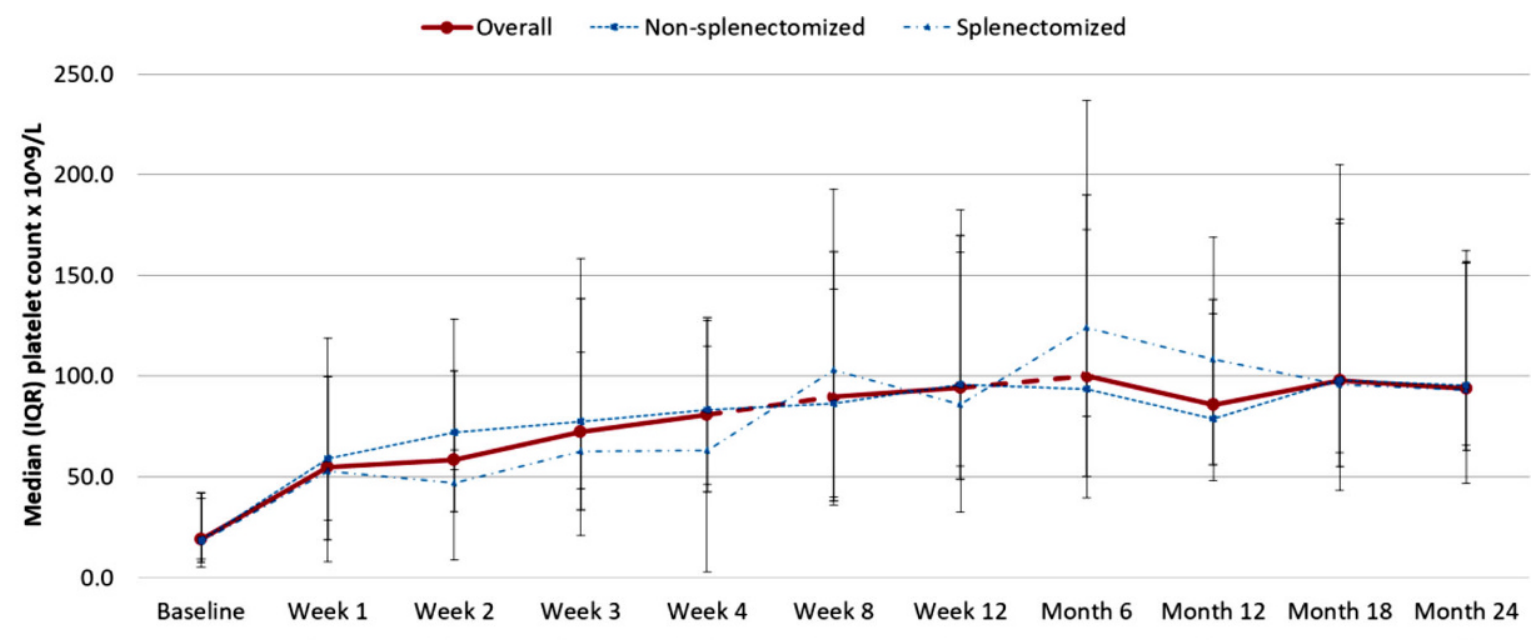

$\mathrm{N}[$ Overall $]=$

$\mathrm{N}$ [Non-splenectomized $]=$ $\begin{array}{llll}100 & 88 & 84 & 76 \\ 64 & 56 & 53 & 48 \\ 36 & 32 & 31 & 28\end{array}$

$36 \quad 32$

$\begin{array}{ll}76 & 80 \\ 48 & 50 \\ 28 & 30\end{array}$

Fig. 1 Platelet count at timepoint relative to romiplostim initiation; IQR interquartile range

recorded medical histories, it was unclear whether patients were contraindicated or objected to splenectomy.

All three studies also showed that romiplostim was used prior to the chronic stage of ITP, as indicated. Chronic ITP is defined as lasting for more than 12 months [8]. In PLATON, the median duration of ITP at romiplostim initiation was 1.92 years with a lower quartile of 0.28 years, showing that numerous patients received romiplostim already at the persistent stage of ITP of 3 to 12 months. In the large international study, romiplostim was also used in newly diagnosed or persistent ITP (34\%) [4]. In the German PLATEAU study, the median duration of ITP at baseline was 25 months [5].

The romiplostim starting dose was generally in line with the label with a median of $1.0 \mu \mathrm{g} / \mathrm{kg} /$ week. However, the range of $1-5 \mu \mathrm{g} / \mathrm{kg} /$ week shows that at least some patients received higher than recommended starting doses. In the international phase IV study, $31 \%$ received higher-than-recommended starting doses [4].

In PLATON, $49 \%$ of patients had $\geq 3$ prior ITP treatments, including corticosteroids (91\%) and IVIg (29\%). As adverse effects of corticosteroids rapidly outweigh their benefits, they should be tapered and stopped after response or after 4 weeks in nonresponders [9]. In PLATON, 96\% discontinued and $29 \%$ started concurrent ITP therapies. The number of patients and treatments, specifically corticosteroids, decreased continuously. In the international phase IV study [4], $55 \%$ had $\geq 3$ prior ITP treatments, including $39 \%$ with off-label rituximab. The proportion of patients previously receiving corticosteroids was comparable in both studies (91\% each) [4], but more patients had previously received IVIg $(72 \%)$ in the international phase IV study [4] compared to PLATON (29\%).
During romiplostim treatment platelet counts normalized to an average median of $>50 \times 10^{9} / \mathrm{L}$. Both, splenectomized and nonsplenectomized patients, experienced a comparable incidence of bleeding and both groups reported fewer bleeding events during treatment with romiplostim. This observation is in line with the other studies, although those studies reported grade 3 or 4 bleeding events despite romiplostim treatment, whereas PLATON did not $[4,5]$. Of 32 patients requiring hospitalizations after initiation of romiplostim, 20 had also required prior hospitalizations. Of 20 patients experiencing any bleeding event after initiation of romiplostim, 15 had also experienced prior bleeding events.

At study end, $25 \%$ of patients were in remission, as assessed by the physicians. In the international phase IV study, $10 \%$ were able to discontinue romiplostim due to a hemostatic platelet count [4]. In both studies, splenectomized and nonsplenectomized patients were able to achieve a remission. Their duration of remission is unknown.

The number of ADRs was substantially lower in PLATON than in the international phase IV study $(4 \%$ versus $22 \%$ with $A D R s, 2 \%$ versus $4 \%$ with serious ADRs) and the German PLATEAU study (no cumulative ADR rate reported, but $\geq 5 \%$ for fatigue, dizziness, nausea, vomiting and diarrhea) at a comparable administered dose $[4,5]$.

This study has limitations inherent to the observational design, especially selection and reporting bias, lack of blinding and no control group. As romiplostim was relatively new on the market, more severe patients may have been selected creating a bias against the general ITP population. In addition, data collected in observational studies may be less complete compared to clinical trials. The reduction in bleeding events may thus be a conservative estimate of the true reduction. 


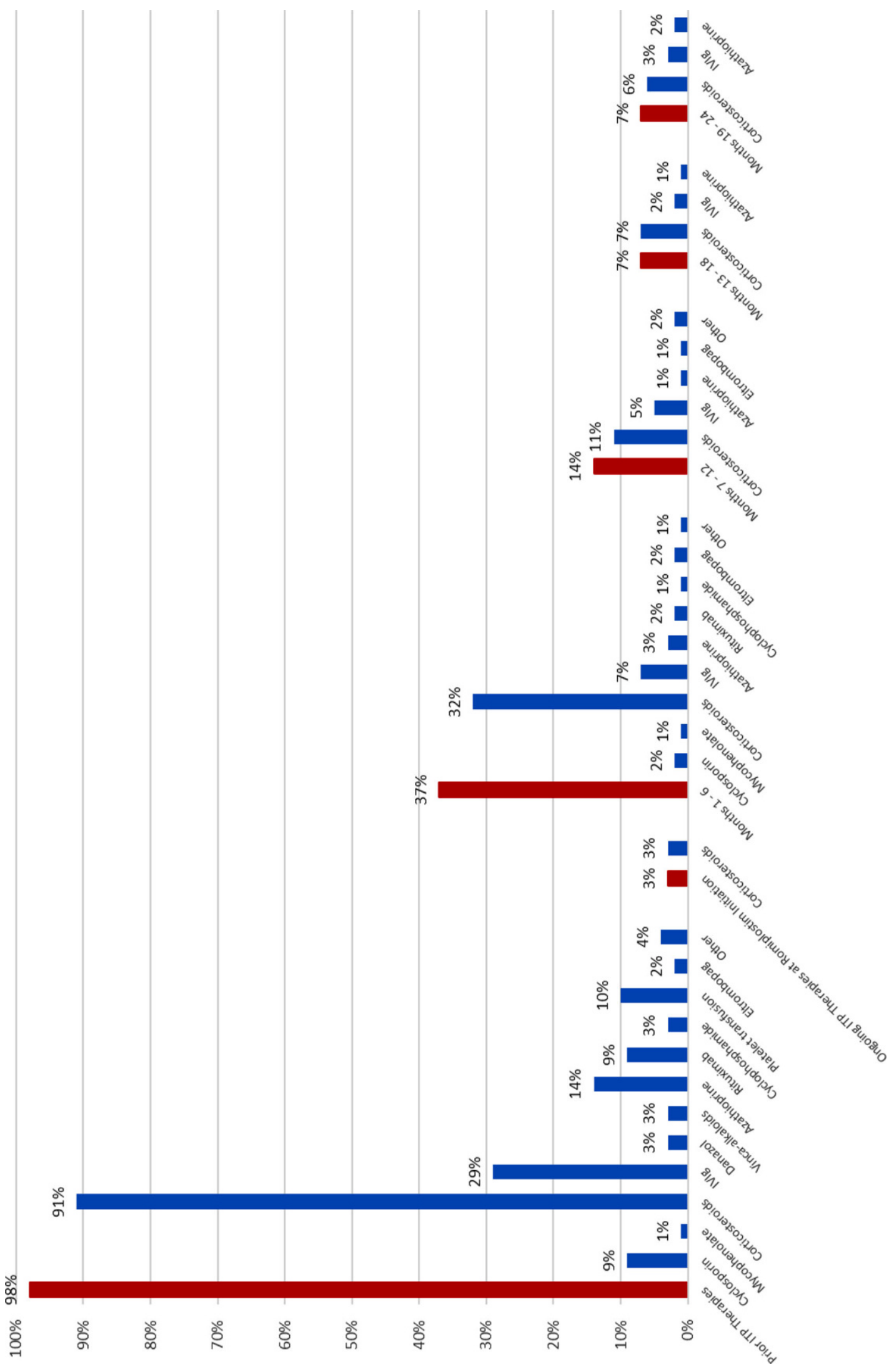

$\frac{1}{0}$

ํํำ

更

है ํํำ

둥요

흥 금

$\stackrel{\oplus}{ }$

ज) ฮे

음

$\mp$

足

등

สำ

ㅇ.

ㄷㅇㅇ 항

원당

这

幽

क्ष.

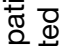

능 옹

을

응 츨

흥

产

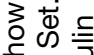

क

这 증

远文

क) $\cong$

을 욛을

응 $\frac{\omega}{\pi}$

0는

全 홍

प्रे है.

空

论 车

ㄷㅇㅇ

तิ

$\varepsilon 0$

ริำ

क क

ง $\mathrm{Q}$

원 
Table 4 Overall summary of adverse drug reactions

\begin{tabular}{|l|l|} 
& $\begin{array}{l}\text { All patients } \\
(N=100)\end{array}$ \\
\hline Patients experienced any ADR & $4(4.0 \%)$ \\
\hline Blood and lymphatic system disorders & $2(2.0 \%)$ \\
\hline Lymphocytosis & $1(1.0 \%)$ \\
\hline Thrombosis & $1(1.0 \%)$ \\
\hline White blood cell counts increased & $1(1.0 \%)$ \\
\hline Cardiac disorders & $1(1.0 \%)$ \\
\hline Heart rate increased & $1(1.0 \%)$ \\
\hline Gastrointestinal disorders & $2(2.0 \%)$ \\
\hline Abdominal pain & $1(1.0 \%)$ \\
\hline Dysphagia & $1(1.0 \%)$ \\
\hline Musculoskeletal and connective tissue disorders & $2(2.0 \%)$ \\
\hline Asthenia & $1(1.0 \%)$ \\
\hline Back pain & $1(1.0 \%)$ \\
\hline Pain in extremity & $1(1.0 \%)$ \\
\hline Nervous system disorders & $2(2.0 \%)$ \\
\hline Headache & $2(2.0 \%)$ \\
\hline Patients experienced serious ADR & $1(1.0 \%)$ \\
\hline Thrombosis & $1(1.0 \%)$ \\
\hline Dysphagia & $1(1.0 \%)$ \\
\hline Patients experienced fatal ADR & 0 \\
\hline $\begin{array}{l}\text { Platelet count closest to first ADR (10 } \\
\text { median (IQR), } n=4\end{array}$ & $92.5(16.5 ; 167.5)$ \\
\hline ADR adverse drug reaction; IQR interquartile range; & $N$ number of patients in \\
\hline Full Analysis Set & \\
\hline Percentages are based on the number of patients in Full Analysis Set \\
\hline 10 different ADR types occurred
\end{tabular}

\section{Conclusions}

Romiplostim dosing, effectiveness and safety in these unselected ITP patients seemed comparable with observations from similarly designed observational studies. After initiation of romiplostim, platelet counts rapidly increased to hemostatic levels and the observation-adjusted incidence rate of bleeding declined to approximately one-third. Of patients who experienced bleeding three quarters had already had prior bleeding events. Remissions were achieved in one quarter of patients.

\section{Take home message}

- The results of this study show that clinical efficacy of romiplostim in the routine practice setting was comparable to its clinical efficacy in other studies of realworld practice.

- The median platelet count increased to $>50 \times 10 \% / \mathrm{L}$ within one week of romiplostim initiation.

- The exposure-adjusted incidence of bleeding was reduced from 131 to 42 events per 100 patient-years after the initiation of romiplostim.

- At the end of study, $25 \%$ of patients achieved remission from ITP.
Acknowledgements Margit Hemetsberger, PhD, of hemetsberger medical services, Vienna, Austria, assisted with the preparation of this manuscript and was funded by Amgen.

Funding This study was sponsored by Amgen.

Author Contribution Daniela Niepel was responsible for the conception and design of the study. Georgi Mihaylov, Zusana Sninska, Nikolai Tzvetkov, Barbara Skopec, and Peter Cernelc were responsible for patient data collection and acquisition of data. Katja Bjorklof was responsible for data cleaning and site queries. Vladlen Ivanushkin conducted statistical programming and analysis. All authors were responsible in the interpretation of the data, and review and critical appraisal of the manuscript.

Conflict of interest G. Mihaylov, Z. Sninska, N. Tzvetkov, O. Cerna, V. Ivanushkin, and P. Černelč declare that they have no competing interests. B. Skopec has received consulting fees from Amgen and Novartis. K. Björklöf and D. Niepel are employees of Amgen and hold Amgen stock.

Open Access This article is licensed under a Creative Commons Attribution 4.0 International License, which permits use, sharing, adaptation, distribution and reproduction in any medium or format, as long as you give appropriate credit to the original author(s) and the source, provide a link to the Creative Commons licence, and indicate if changes were made. The images or other third party material in this article are included in the article's Creative Commons licence, unless indicated otherwise in a credit line to the material. If material is not included in the article's Creative Commons licence and your intended use is not permitted by statutory regulation or exceeds the permitted use, you will need to obtain permission directly from the copyright holder. To view a copy of this licence, visit http://creativecommons.org/licenses/by/4.0/.

\section{References}

1. Kuter DJ, Gernsheimer TB. Thrombopoietin and platelet production in chronic immune thrombocytopenia. Hematol Oncol Clin North Am. 2009;23(6):1193-211.

2. TerrellDR, BeebeLA, VeselySK, Neas BR, SegalJB, GeorgeJN. The incidence of immune thrombocytopenic purpura in children and adults: a critical review of published reports. Am J Hematol. 2010;85(3):174-80.

3. Kuter DJ, Bussel JB, Lyons RM, Pullarkat V, Gernsheimer TB, Senecal FM, et al. Efficacy of romiplostim in patients with chronic immune thrombocytopenic purpura: a double-blind randomised controlled trial. Lancet. 2008;371(9610):395-403.

4. Steurer M, Quittet P, Papadaki HA, Selleslag D, Viallard JF, Kaiafa $\mathrm{G}$, et al. A large observational study of patients with primary immune thrombocytopenia receiving romiplostim in European clinical practice. Eur J Haematol. 2017;98(2):112-20.

5. Welslau M, Reiser M, Illmer T, Josten K, Dietzfelbinger H, Seitz A. Treatment of adults with primary immune thrombocytopenia (ITP) with romiplostim in routine clinical practice in Germany-interim results from an observational study (PLATEAU). Haematologica. 2014;99(1):204.

6. Miller AB, Hoogstraten B, Staquet M, Winkler A. Reporting results of cancer treatment. Cancer. 1981;47(1):207-14.

7. Heddle NM, Cook RJ, Webert KE, Sigouin C, Rebulla P. Biomedical excellence for safer transfusion working party of theinternational society for blood T. Methodologicissues in the use ofbleeding as an outcomein transfusion medicine studies. Transfusion. 2003;43(6):742-52. 
8. Rodeghiero F, Stasi R, Gernsheimer T, Michel M, Provan D, Arnold DM, et al. Standardization of terminology, definitions and outcome criteria in immune thrombocytopenic purpura ofadultsand children: reportfromaninternational working group. Blood. 2009;113(11):2386-93.

9. Provan D, Stasi R, Newland AC, Blanchette VS, BoltonMaggs P, Bussel JB, et al. International consensus report on the investigation and management of primary immune thrombocytopenia. Blood. 2010;115(2):168-86.

Publisher's Note Springer Nature remains neutral with regard to jurisdictional claims in published maps and institutional affiliations.

- For latest news from international oncology congresses see: http://www.springermedizin.at/ memo-inoncology 